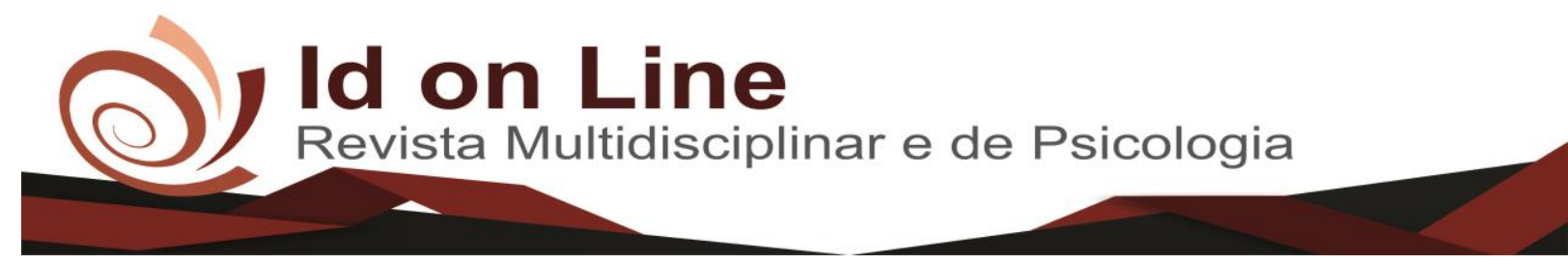

Artigo

\title{
Gestão da Qualidade com Foco no Atendimento ao Cliente: Estudo Realizado na Cidade de Mauriti-CE
}

Luciene de Lucena Bento ${ }^{1}$; Márcia Maria Leite ${ }^{2}$

\begin{abstract}
Resumo: O presente artigo abrange a qualidade no serviço de atendimento ao cliente, que ocasiona satisfação ao consumidor, tendo por objetivo geral avaliar o grau de satisfação dos clientes quanto ao serviço ofertado pelo comércio da cidade de Mauriti-CE. A metodologia baseia-se em uma pesquisa bibliográfica, com abordagem quantitativa de cunho descritiva, por meio de uma pesquisa de opinião realizada com os consumidores do comércio da cidade citada. $\mathrm{O}$ instrumento de coleta aconteceu por intermédio de um questionário, contemplando 12 perguntas entre abertas e fechadas. Em formas de resultados, identificou o grau de satisfação dos clientes em relação ao comércio da cidade de Mauriti, analisando que os serviços de atendimento oferecidos pelas empresas do comércio da referida cidade, não está conivente com as necessidades e aptidões dos consumidores.
\end{abstract}

Palavras-Chave: Atendimento. Qualidade. Comportamento do Consumidor. Satisfação.

\section{Quality Management with Focus on the Customer Service: A Study conducted in the City of Mauriti in the State of Ceará}

\begin{abstract}
The present article includes the quality in the service service to the customer, that causes satisfaction to the consumer, tends for general objective to evaluate the degree of the customers' satisfaction as for the service presented by the trade of the city of Mauriti-CE. The methodology bases on a bibliographical research, with descriptive quantitative approach of stamp, through an opinion research accomplished with the consumers of the trade of the mentioned city. The collection instrument happened through a questionnaire, contemplating 12 questions between open and closed. In forms of results, it identified the degree of the customers' satisfaction in relation to the trade of the city of Mauriti, analyzing that the service services offered by the companies of the trade of the referred city, it is not connivent with the needs and the consumers' aptitudes.
\end{abstract}

Keywords: Service. Quality. Behavior of the Consumer. Satisfaction.

\section{Introdução}

Na contemporaneidade do mercado a satisfação do cliente é necessária para uma organização evoluir no seguimento em que atua, visto que a satisfação do consumidor fornece fatores que impactam no avanço da valorização empresarial e ampliações de resultados eficientes para satisfazer expectativas e necessidades (KOTLER, 2012).

\footnotetext{
${ }^{1}$ Graduanda em administração, Centro Universitário Doutor Leão Sampaio, Juazeiro do Norte, Ceará, Brasil. Contato: lucienefinanceiroceara@gmail.com

${ }^{2}$ Especialização em gestão estratégica de pessoas, Centro Universitário Doutor Leão Sampaio, Juazeiro do Norte, Ceará, Brasil. Contato: marcialeite@leaosampaio.edu.br
}

761 Id on Line Rev. Mult. Psic. V.12, N. 42, p.746-760, 2018 - ISSN 1981-1179
Edição eletrônica em http://idonline.emnuvens.com.br/id 
Segundo dados de uma pesquisa realizada por uma empresa sueca a Butter Business World Wide no final do ano de 2017, sobre simpatia no atendimento ao cliente, o Brasil ocupa o penúltimo lugar, em um ranking de 16 países, como um dos menos simpáticos do mundo no atendimento ao cliente.

Carvalho (2010) menciona que no atendimento ao cliente deve-se haver qualidade, simpatia e rapidez agregada, afinal é um serviço que está sendo oferecido ao consumidor no ato da compra. Em vista deste argumento, como a qualidade agregada ao atendimento impacta na satisfação ao consumidor? Para compreender esta problemática, surgi algumas hipóteses como exemplo, o atendimento é capaz de alterar todo o processo de uma empresa; um atendimento de qualidade proporciona o aumento das vendas; fornecer ao cliente um bom atendimento é o método mais importante que se pode existir em uma empresa.

O presente artigo tem por objetivo geral avaliar o grau de satisfação dos clientes quanto ao serviço ofertado pelo comércio da cidade de Mauriti-CE. Como objetivos específicos, analisar as principais dificuldades no atendimento no ponto de vista do cliente, identificar as causas que precisam melhorar na hora de atender o cliente e verificar o comportamento das organizações percebidas pelo cliente.

O referido estudo justifica-se pelo interesse pessoal em saber o grau de satisfação dos clientes, quanto ao atendimento prestado pelo comércio da cidade de Mauriti-CE. Em termos acadêmicos, o presente artigo destaca como um acesso rápido e compreensivo a informações sobre a qualidade, atendimento e satisfação do consumidor, servindo então como fonte de pesquisa e conhecimento para futuros leitores ou acadêmicos.

\section{Fundamentação Teórica}

\section{Gestão Estratégica}

O estudo sobre gestão estratégica é compreender que as aplicações dos processos utilizados nas organizações servem para melhorar o desempenho de obtenção dos resultados que se esperam, envolvendo a administração estratégica, tomadas de decisões necessárias para gerar a satisfação ao consumidor e diferencial competitivo. (SERRA, FERREIRA e TORRES, 2014). A figura 01 ilustra os principais componentes para a gestão estratégica. 
Figura 01: Componentes da Gestão Estratégica.

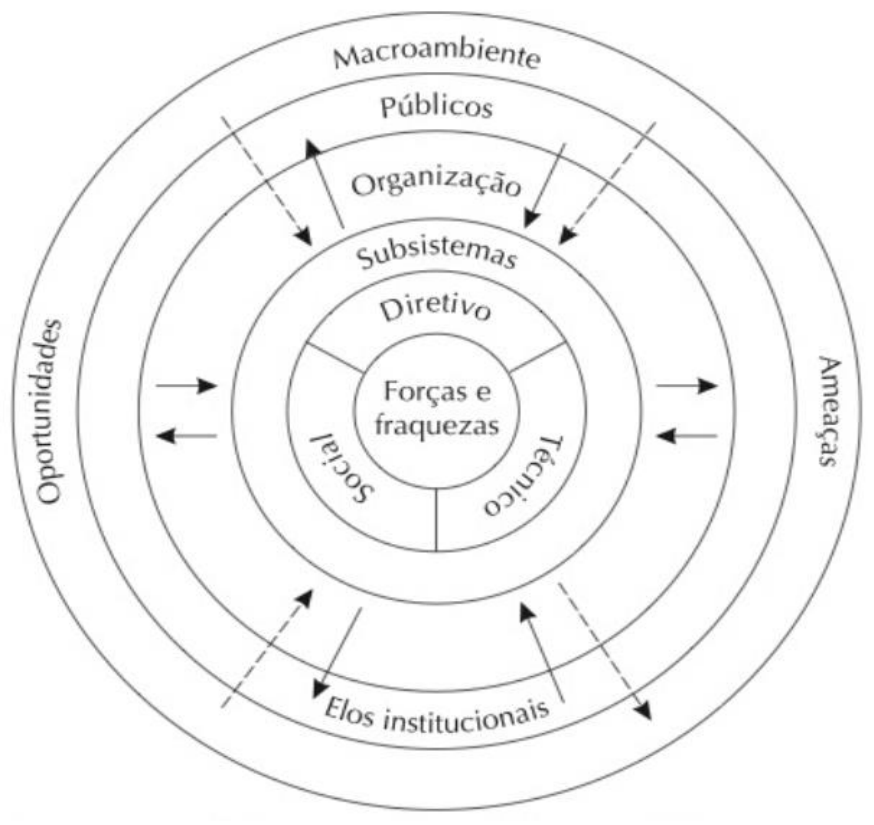

Fonte: Extraído de Tavares (2010).

A figura 01 relaciona-se aos componentes da gestão estratégica, sincronizando cada aspecto relacionando ambiente, público e organização. Destacando que no ambiente encontram-se as ameaças e oportunidades pertinentes a qualquer tipo de organização. Tavares (2010) diz que o diretivo relaciona subsistemas das técnicas de decisão relacionada à empresa, que define o crescimento no meio do mercado competitivo. O técnico são processos que desenvolvem a organização, com apoio nas decisões tomadas, provendo retorno das atuações realizadas e constituído para o desenvolvimento organizacional. O social estabelece as ações particulares e de grupos, ampliando outros subsistemas, buscando aumentar a capacidade de alcance dos resultados de cada individuo e procurando a satisfação dos clientes.

As empresas precisam instituir a diferenciação, inovando nas atividades empresariais, criando meios que desperte o sucesso e desenvolvimento de mudanças competitivas através dos serviços fornecidos aos clientes (SERRA, FERREIRA e TORRES, 2014).

Para Alvarez (2015) os serviços utilizados nas empresas, em ação de atender o consumidor, necessitam da colaboração do vendedor, treinamento e inovação, sendo estas citadas, estratégicas para satisfazer o cliente. Percebe-se que a gestão estratégica pode adotar medidas para relacionar qualidade e atendimento, principalmente quando se objetiva satisfação e confiabilidade em um serviço prestado, porém vale ressaltar que para o alcance deste sucesso, a gestão deve considerar o comportamento do 
consumidor, conhecer o cliente, saber o que este espera ao entrar na empresa e principalmente, sempre agregar qualidade ao atendimento (ALVAREZ, 2015).

\section{Qualidade no Atendimento}

Paladini (2012) apresenta que a qualidade surgiu para medir o grau de melhoria dos produtos e serviços dentro das empresas, abrangendo diversos meios, com diferentes formas de análise, incidindo que este conceito ocorre de maneira satisfatória, pois o consumidor pode identificar e entender de várias formas.

A qualidade evoluiu ao longo do século XX, ocorrendo procedimentos importantes sobre a verificação de produto, adequação de sistemas e desenvolvimento da segurança na qualidade, contudo na década de 90 começaram as análises que a qualidade não necessitaria estar ao nível de culminância técnica e sim possuir métodos para atender o cliente com requisitos exigidos, obtendo uma avaliação na satisfação do cliente quanto ao uso do produto ou serviço oferecido (CARPINETTI e GEROLAMO, 2015).

Segundo Defeo e Juran (2015) a busca pela qualidade superior oferece as empresas uma elevação adequada sobre o desempenho da satisfação, tendo em vista que é importante a gestão e colaboradores seguirem estratégias que desenvolva este conceito de qualidade para a obtenção de resultados esperados, pois as organizações só conseguem a fidelização do cliente quando os bens ou serviços excedem todas as expectativas dos consumidores.

Como exemplo disto, os autores Paladini e Bridi (2013) menciona a importância de avaliar a qualidade e satisfação, pois beneficia o cliente com estratégias que mostram a visão ampla de todo processo fornecido pela organização, através de métodos que relacionam com o consumidor, desempenhando melhorias e inserindo medidores para indicar priorização na conquista da fidelização de toda clientela, por meios de bens disponibilizados adequadamente.

A qualidade ofertada por uma empresa precisa seguir princípios que possa garantir à satisfação do cliente, mantendo alinhada aos processos apropriados, como treinamento de colaboradores no cumprimento das atividades com credibilidade, desenvolvimento de uma postura ética e criação de mecanismos para gerar ou medir o grau de satisfação dos consumidores com o atendimento prestado pela organização (CARVALHO e MORAIS, 2010). Segundo Kotler (2012) a satisfação é o grau de percepção positiva que o consumidor demostra em relação a um produto, serviço ou empresa, 
compreendido como sensação de prazer relevante ao comparar o esperado pelo cliente com o realizado pela organização.

A palavra qualidade é de domínio público, no entanto não pode ser utilizada de qualquer maneira, visto que os conceitos incorretos a respeito deste termo poderão levar a gestão a realizar atitudes erradas, aonde o reflexo conduzirá a perda da competitividade, fazendo necessária uma definição mais plausível a respeito da qualidade (CARVALHO e PALADINI, 2012).

A gestão de qualidade total é mencionada por Kotler (2012) como uma abordagem que procura melhoria continuada dos processos produtivos e organizacionais, compreendido por o grau positivo que um bem é apresentado ao cliente, almejando a satisfação e superação das expectativas. Este autor cita que a qualidade também está relacionada ao atendimento ao cliente, uma vez que além de produtos, a empresa disponibiliza de um atendimento eficiente, mantendo bem-estar e comodidade ao consumidor no ato da realização de compras.

A qualidade no atendimento entrelaça aspectos de ética com o cliente, seguido por respeito, bom trato, prestação de serviço, ouvidoria e atendimento pós-compra, enfatizando que este apoio de boa conduta com o consumidor pode acontecer presencialmente, exemplificando em loja ou estabelecimento empresarial e a distância, como via internet ou telefone, vale pontuar ainda a importância das empresas conhecerem o consumidor, em especial o termo 'clientes', considerando que estes são uma peça fundamental para o sucesso de qualquer empresa (CARVALHO e PALADINI, 2012).

\section{Clientes}

No final do século XX, especificamente no início da década de 1990, começaram a desenvolver títulos de valorização do cliente para as organizações, vista a importância destes na existência do crescimento e qualidade nas empresas (DANTAS, 2014). Este autor menciona também que as empresas podem possuir as melhores estruturas físicas e sistemas qualificados, mas se não existir o cliente para adquirir produtos e serviços, não há sobrevivência para nenhum tipo de negócio, jugando que o objetivo principal é atender as necessidades e desejos dos clientes, buscando sempre meios de satisfazê-los.

Segundo Silva e Zambon (2012) o cliente é uma peça fundamental que deve existir em toda e qualquer integração empresarial, levando em conta a inconsistência de qualquer tipo de organização, seja esta pública, privada, com ou sem fins lucrativos, que não tenham cliente.

É importante perceber o sentido da palavra cliente, a fim de assimilar a responsabilidade no sentido de um atendimento com qualidade e agilidade, sem a necessidade de passar por 
constrangimentos desnecessários, pois há uma diferença do cliente comprador, usuário e pagante: $\mathrm{O}$ comprador busca por meios da facilidade a elevação do atendimento, variedade ou conhecimentos que o valorize; o usuário é formado por opiniões e avaliações como dicas de sabor, caimento de uma roupa ou informações de resistência do produto ou manutenção de serviços; o pagante aquele voltado à forma de pagamento preço e os meios utilizados para pagar os valores (SILVA e ZAMBON, 2012).

Wellington (2011) salienta que um cliente satisfeito é um consumidor fiel, que procurar a organização mais vezes para ser atendimento com excelência e competência, mesmo resolvendo pagar por um valor a mais na prestação de serviço de qualidade.

Kotler (2012) afirma que para atrair e conservar clientes, as empresas necessitam seguir uma padronização de metas, entendendo que o alvo principal é fidelizar clientes, preocupando-se em proporcionar produtos de qualidade, com atendimento voltado a beneficiar o consumidor, para obter a satisfação ou novos clientes.

Ainda existem clientes internos e externos, o primeiro corresponde ao pessoal que desenvolve as atividades dentro do contexto organizacional, colaboradores, o segundo aos que procura comércio físico ou visual para realização de compras (SILVA e ZAMBON, 2012).

O cliente é a peça chave para um bom funcionamento do negócio, todavia é necessário compreender o que o cliente espera ao entrar em uma organização, no sentido de geração de valor, atendimento, satisfação e comodidade (OLIVEIRA, 2011). O cliente espera ser bem atendido, quando estiver à disposição da empresa para realizar uma compra, pontuando ainda a existência da qualidade na prestação deste serviço em relação à organização.

\section{O que o Cliente espera ao entrar em uma Organização}

Oliveira (2011) relata que na satisfação do cliente faz necessário o envolvimento de todos os processos das organizações, unificado para a prestação de atendimento qualificado ao cliente interno e externo, sendo o objetivo principal, por isso é importante à inovação, melhorias e mudanças com técnicas administrativas capaz de atender os possíveis produtos e serviços exigidos por toda clientela.

Cobra (2015) apresenta que o cliente busca nas organizações um bom atendimento, pautando que a volta de um consumidor aos estabelecimentos é resultado da maneira como foi atendido, levando em consideração a valorização deste cliente, estratégias para descobrir o desejam, inovação da qualidade do produto ou serviço e pesquisas de preços concorrentes. O remete ainda, que para isto acontecer é importante que gerentes, colaboradores e fornecedores estejam conectados com mesmo sentido de 
realizar um bom serviço.

Conforme Gianesi e Corrêa (2012) o cliente sempre avalia se a empresa atende suas necessidades, havendo uma perspectiva, entendendo que esta se torna mais forte que a própria necessidade, assim a organização deverá focar principal em atendê-lo bem. É importante a empresa está sempre alinhando quais os pontos de influência que o cliente analisa. A figura 02 apresenta quatro fatores de influências para o cliente identificar uma empresa.

Figura 02: Fatores de Influência para Identificar uma Empresa.

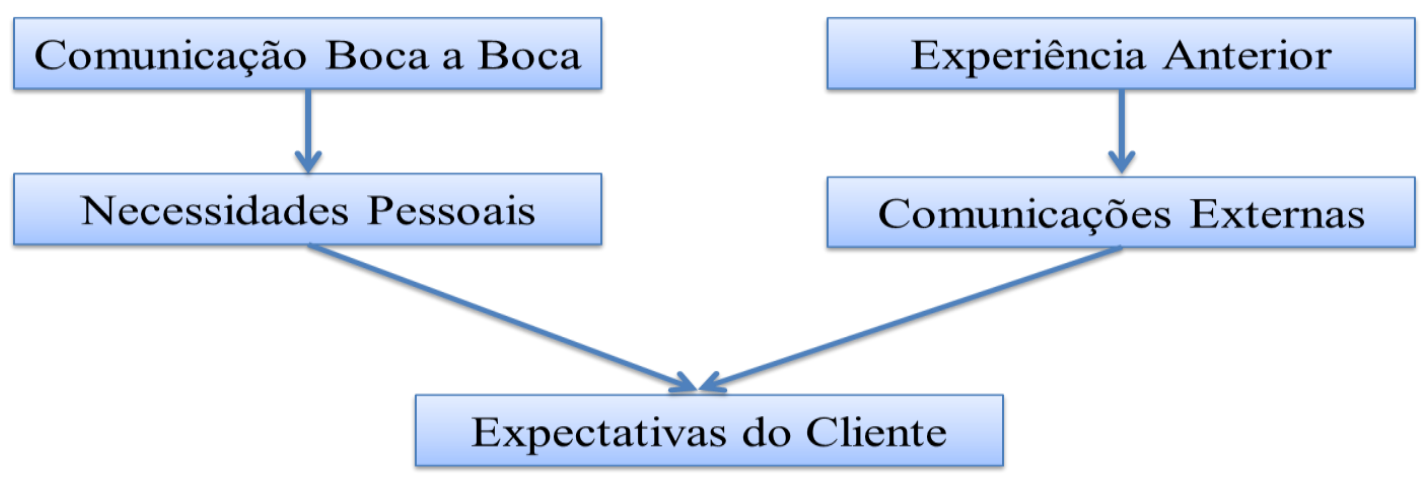

Fonte: Adaptação de Gianesi e Corrêa (2012)

Com base na figura 02 Gianesi e Corrêa (2012) afirmam que comunicação boca a boca são instruções repassadas por terceiros, recomendando um serviço em procura, com fundamentação de qualidade para realizar as compras. Na experiência anterior existe a busca por conhecimento do serviço, influenciando a perspectiva do cliente com relação à qualidade do atendimento, tempo de entrega e outros processos da organização.

As necessidades pessoais são consideradas pelo cliente o serviço prestado antes, durante ou depois das compras, enfatizando todas as expectativas que se almeja, adotando o conhecimento que as expectativas superam as próprias necessidades, já as comunicações externas caracterizam como a devolução de todo processo ocorrido dentro da organização, se foi satisfatório ou correspondidas, ficando esclarecido que as expectativas realizadas contêm extensões para elevação da empresa, onde o cliente sempre usa as informações externas, mesmo que não atenda as necessidades (GIANESI e CORRÊA, 2012).

Para Alvarez (2015) o sucesso e lucratividades geral, as empresas necessitam buscar ferramentas 
capazes de atender o cliente, oferecer produtos e serviços inovadores e desenvolver mudanças que possam gerar vantagens competitivas no mercado atuante. De acordo com o autor, para manter o cliente fiel à organização é importante existir métodos que acompanhe o consumidor até o pós-compra, passando confiança e comprometimento, deixando esclarecido que o processo de venda nunca acaba no devido fechamento de um pedido, é nesse estágio que o gerente pode obter noções sobre o comportamento do consumido.

O comportamento do consumidor exerce descaminhos na hora de realizar uma compra, com isto, caso a percepção da qualidade no atendimento não seja identificada, torna-se um estímulo contrário para finalizar a compra (LAS CASAS, 2017).

\section{Comportamento do Consumidor}

O comportamento do consumidor para Las Casas (2017) é o conjunto de fatores psicossociais que impulsionam os clientes a comprar. Segundo o autor, desde a identificação das necessidades e desejos, informações das ofertas, seleção, realização da compra, consumo, descarte e avaliação, o consumidor é influenciado por fatores socioculturais, pessoais, situacionais ou marketing, como representados na figura 03 .

Figura 03: Fatores influenciadores do comportamento do consumidor.

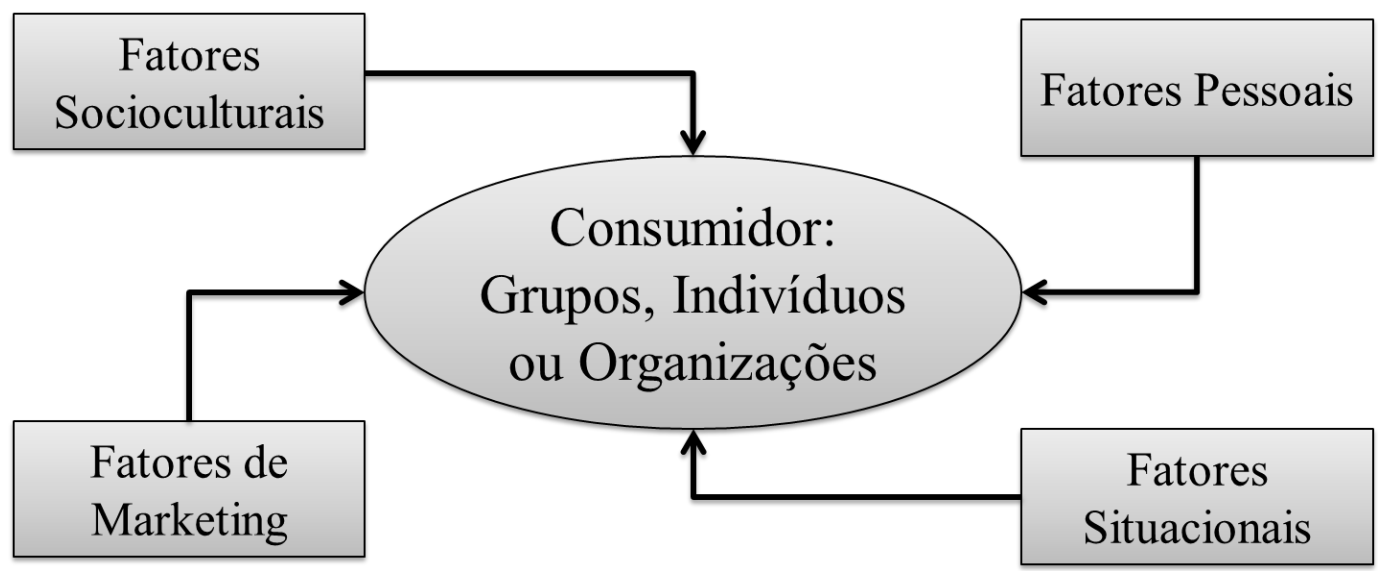

Fonte: Adaptação de Limeira (2017). 
Considerando a figura 03, Limeira (2017) apresenta que o consumidor é influenciado por questões socioculturais, relacionado à classe social, cultura, família, religião e outros aspectos inerentes ao ambiente que o cliente está inserido. As influências pessoais correspondem aos estímulos psicológicos do consumido, como individualidade, motivação, percepção e aprendizado. Em relação ao marketing, a influência está ligada aos estímulos das propagandas e campanhas nas mídias sociais. Por fim os fatores situacionais, correlacionados aos aspectos do cotidiano dos indivíduos, enquanto consumidores.

De acordo com Samara e Morsch (2012) o marketing é o maior influenciador em termos de decisão de compra do consumidor, visto a satisfação das necessidades e desejos das pessoas, dado como papel principal atribuindo para o marketing, atribuindo qualidade e fidelização contínua aos clientes e proporcionado benefícios para organização no sentido de lucratividade. Kotler (2012) define marketing como uma ferramenta capaz de gera bens e serviços para satisfazer alguma necessidade de um mercado, através da promoção de vendas.

Vale salientar que o comportamento do consumidor interfere no processo de decisão de compra, considerando que este ocorre na mente do cliente, quando ocorre uma necessidade ou desejo, entrelaçado por algum fator de influência, levando o consumidor a decide ou rejeita uma compra, podendo manifesta fidelização caso a percepção do produto ou serviço satisfaça o cliente (SALOMON, 2016).

Sabendo que o cliente é influenciado ao consumo, fica notória a importância das organizações abordarem meios que conquiste o consumidor, por exemplo, agregar qualidade no atendimento, conhecer o próprio cliente e estudar a formação do comportamento do consumidor antes e após uma venda (COBRA, 2015).

O cliente se vê na obrigação de exigir opções vantajosas da empresa, fazendo necessário então haver uma compreensão do comportamento do indivíduo em quanto consumidor, entendendo o que este necessita, deseja, sonha ou repudia, buscando atendê-lo da melhor forma possível (SAMARA e MORSCH, 2012).

\section{Metodologia}

Quanto os meios utilizados para este artigo, optou-se por um estudo de opinião por se tratar em buscar conhecer atitudes, pontos de vista e preferências que as pessoas têm sobre algum assunto, serviço, produto. Como também conhecer interesses, comportamentos, falhas entre outros. No âmbito organizacional esta pesquisa tem como objetivo auxiliar em tomadas de decisão (ALMEIDA, 1996).

769 Id on Line Rev. Mult. Psic. V.12, N. 42, p. 746-760, 2018 - ISSN 1981-1179

Edição eletrônica em http://idonline.emnuvens.com.br/id 
Esta pesquisa fundamentou-se com bases bibliográficas realizada em livros e caracterizando-se quanto ao procedimento em pesquisa de campo, pois abrange o estudo de um ambiente por meio do levantamento de dados, sendo de cunho descritivo, levando em consideração a busca por informações sobre as eventualidades discutidas na teoria (SEVERINO, 2016). A abordagem é quantitativa, pois se caracteriza em tabular e mensurar de forma estatística, dados coletados em um ambiente delimitado, buscando opinião e conotações acerca de um fenômeno (SEVERINO, 2016).

A pesquisa foi realizada no centro comercial da cidade de Mauriti, localizada no estado do Ceará, situada na mesorregião sul, a 496,6 Km da capital Fortaleza. O município inclui áreas geográficas com abrangências do clima semiárido, rico pela agricultura e grandes fatos históricos, coletado nas habitações. Como sujeitos da pesquisa foram abordados 200 (duzentas) indivíduos que estavam disponíveis no centro comercial da cidade de Mauriti, sendo do gênero masculino e feminino com faixa etária entre 18 a 50 anos, pré-dispostos em participar.

A amostra da pesquisa foi determinada pela acessibilidade ao participante. A coleta de dados foi realizada por meio de questionários, contendo 12 perguntas, entre fechadas e abertas. Quanto ao critério de inclusão, foram englobados todos os sujeitos prontificados em participar da pesquisa por conveniência (SEVERINO, 2016).

Todavia em caráter de exclusão, aqueles que estejam no local da pesquisa, porém não apresentaram interesse em participar ou atendeu a faixa etária, conforme estabelecida. Para o procedimento de tratamento dos dados foi utilizado o software Excel, a escolha pelo software deu-se por ser uma ferramenta que possibilita apresentar os resultados em formato de gráficos. Quanto a análise dos dados foi feito o alinhamento, interpretação e compreensão entre os resultados obtidos na pesquisa e a fundamentação teórica apresentada neste artigo.

\section{Análise e Discussão dos Resultados}

A pesquisa foi realizada por meio de questionários para 200 (duzentos) indivíduos que frequentam os comércios da Cidade de Mauriti, localizada no estado do Ceará, situada na mesorregião sul, a 496,6 Km da capital Fortaleza, sendo realizada a pesquisa entre os dias 04 até dia 11 de agosto de 2018, durante horário comercial das 08:00 horas até ás 12:00 horas. Os clientes responderem perguntas para avaliar o grau de satisfação que as empresas ofereciam aos consumidores, revelando quais os motivos que levam os mesmo a comprarem. Foram aplicadas também perguntas abertas para identificar opiniões do cliente em relação aos serviços ofertados, podendo mensurar as sugestões de melhorias 
sobre avanços de crescimento das organizações de acordo com a percepção do cliente, apresentando características que obtém influências para os resultados de alcance da empresa. O gráfico 01 apresenta a idade e gênero dos participantes da pesquisa.

\section{Gráfico 01: Idade e Gênero}

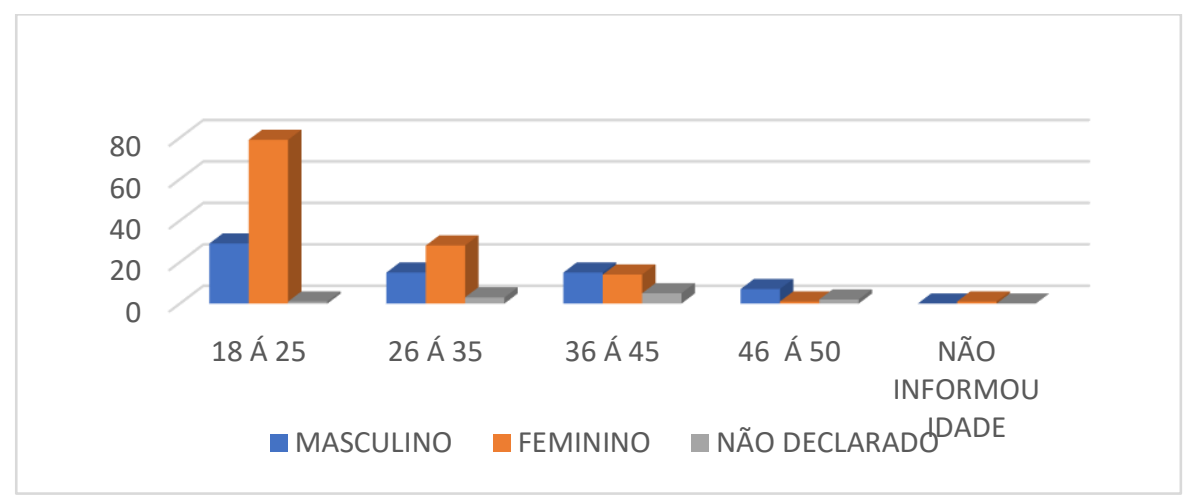

Fonte: Dados da pesquisa 2018.

Através do Gráfico 01, pode-se observar que das 200 pessoas entrevistadas, o público feminino se destacou, sendo que $75 \%$ estão em uma faixa etária entre 18 e 25 anos. Em seguida aparece o público masculino com a mesma faixa etária, correspondendo a $25 \%$. O gráfico 02 apresenta os resultados referentes à avaliação dos serviços oferecidos pelas empresas de Mauriti-CE.

Gráfico 02: Avaliação dos serviços oferecidos pelas empresas de Mauriti - CE.

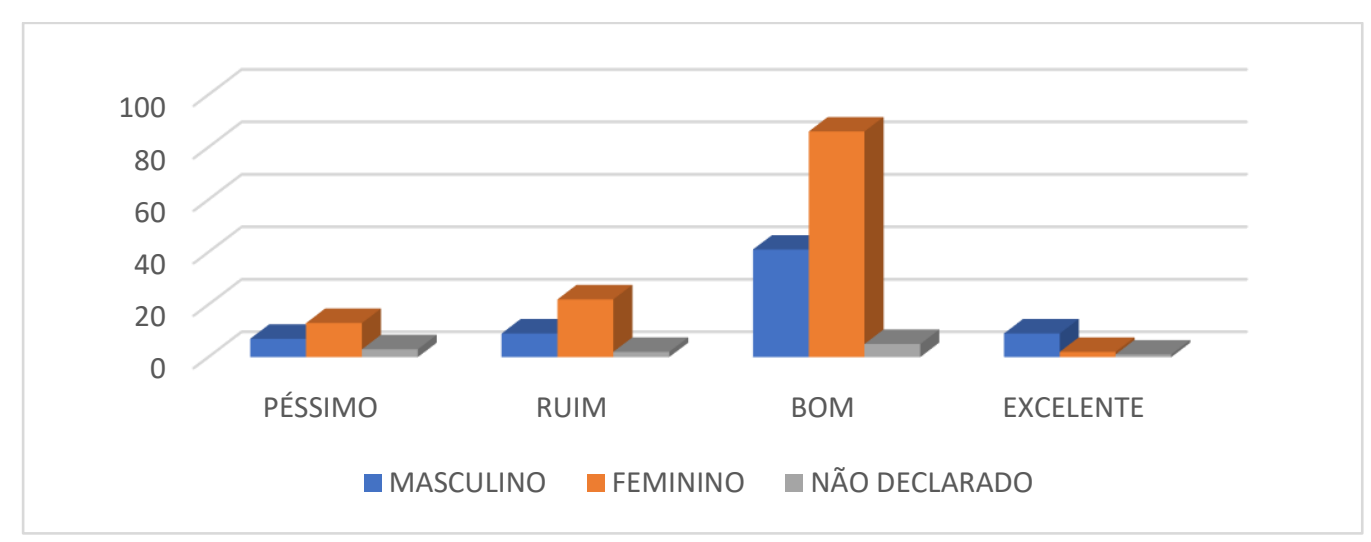

Fonte: Dados da pesquisa 2018.

No Gráfico 02 , verificou-se que a maioria do público feminino avalia os serviços ofertados no comercio de Mauriti como bom. Porém é notório que existe uma incidência entre péssimo e ruim deste mesmo público e ainda a incidência de excelente. O público masculino apontou em menor numero, 
comparado ao feminino, que os serviços oferecidos é bom. No entanto aparece no gráfico a ocorrência de péssimo, ruim e excelente.

Nota-se que os serviços fornecidos pelas empresas, apresentados no gráfico 02, obteve maioridade no índice bom, mais deve ser levado em consideração que há uma grande relevância de não satisfatório, destacando que as organizações devem mostrar preocupação para mudar este número, buscando estratégias para oferecer o melhor serviço ao cliente e fazendo com que o consumidor se sinta valorizado, como menciona Gianesi e Corrêa (2012).

Gráfico 03: Os atendentes oferecem informações de qualidade para suas perguntas sobre produto ou serviço ofertado.

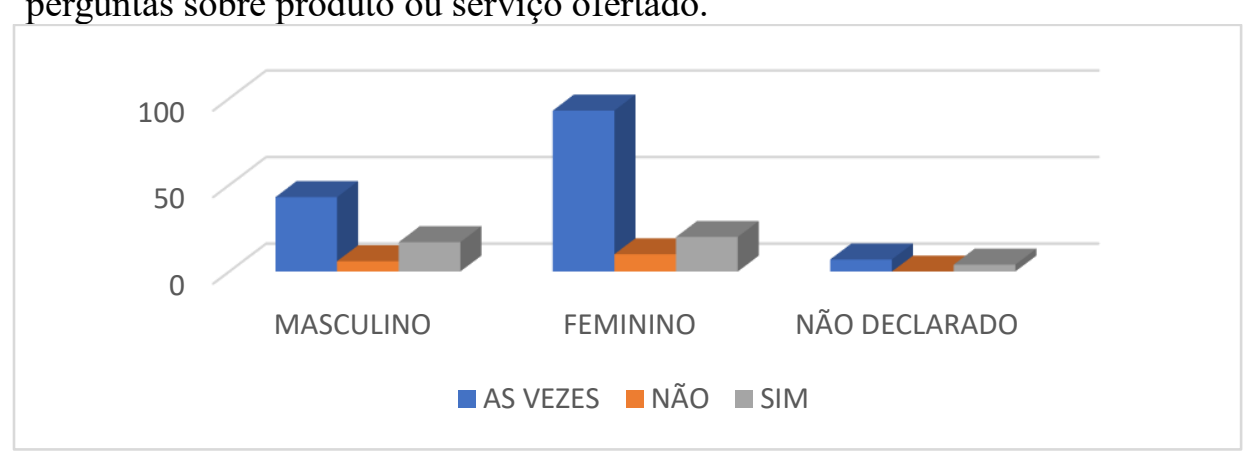

Fonte: Dados da pesquisa 2018.

No gráfico 03 a maioria do público feminino, seguido de uma parcela considerável do público masculino entrevistado, declarou que "às vezes" recebem as informações de qualidade, referente a perguntas sobre um produto ou serviço ofertado. Percebe-se também que aparecem respostas de ambos os públicos, apontando que não recebem quaisquer informações de qualidade. Na sequência é visto que alguns destacam que recebem qualidade nas informações.

De acordo com análise do gráfico 03 os atendentes devem oferecer informações de qualidade para as perguntas dos clientes com relação ao serviço e produto, entendendo que para conseguir o sucesso que se almeja os colaboradores são responsáveis por adquirir a satisfação dos clientes, em vista disto o processo de informações deve ocorrer todos os dias a partir do momento que o cliente frequente os estabelecimentos, deixado de maneira bem esclarecida para que o cliente não saia com dúvida e sem obtenção de um bom resultado do que se espera. Sabendo que o cliente é influenciado ao consumo, fica notória a importância das organizações abordarem meios que conquiste o consumidor, por exemplo, agregar qualidade no atendimento, conhecer o próprio cliente e estudar a formação do comportamento do consumidor antes e após uma venda como apresenta Cobra (2015). 
Gráfico 04: Cruzamento das variáveis informações de qualidade x rapidez e agilidade.

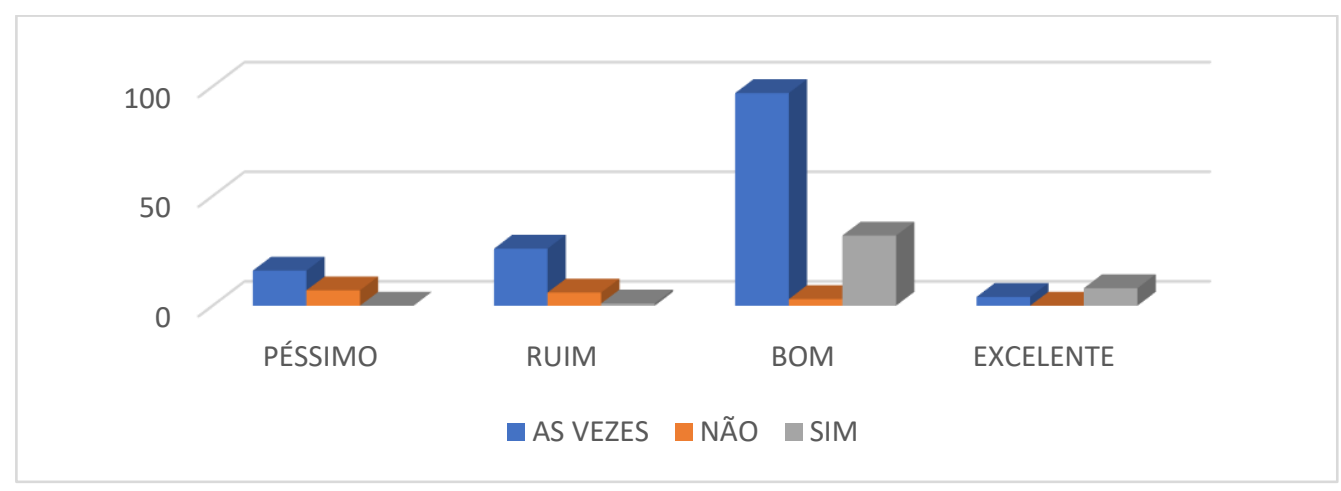

Fonte: Dados da pesquisa 2018.

Observa-se no gráfico 04 , mais de 90 pessoas apontando que às vezes o atendimento é bom, possuindo qualidade, rapidez e agilidade. É visto que os colaboradores não estão bem capacitados para apresentar competências desejáveis pelos consumidores. Percebesse também que as empresas não consegue atender com relevância a excelência nas atividades oferecidas, pois no gráfico 04 há um número mínimo de pessoas que conseguem excelentes resultados sobre os serviços que atenda a expectativas.

Analisa-se que os serviços executados nas empresas não estão alinhados para incidir no cotidiano, os clientes não consegue enxergar a qualidade que se espera ao entrar nos estabelecimentos que frequentam, no entanto a organização deve se preocupar com estes requisitos, pois o cliente está atento a estes procedimentos, podendo passar uma imagem negativa da empresa para outras pessoas que desejam procurar, visto que para a fidelização de um cliente as empresas necessitam atender as metas solicitadas, seguindo uma padronização através de serviços que promova benefícios sobre a qualidade na satisfação voltada ao cliente, como menciona Kotler (2012). 
Gráfico 05: Analise do atendimento fornecido pelo atendente.

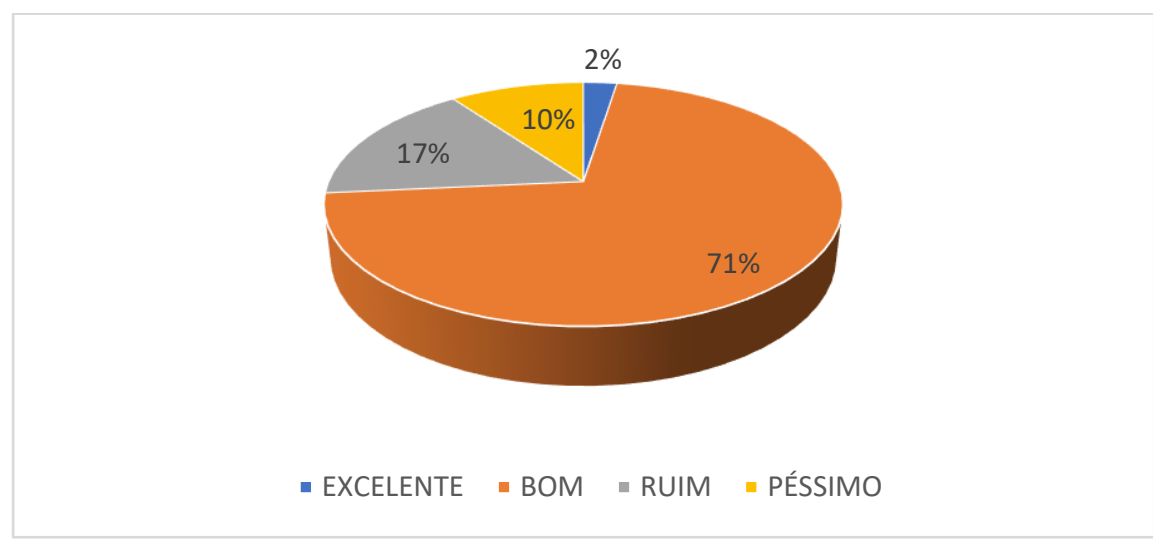

Fonte: Dados da pesquisa 2018.

De acordo com o gráfico 05 , percebemos que $71 \%$ do público investigado apontam que o atendimento oferecido para os clientes é Bom. 17\% dizem ser Ruim o atendimento. 10\% dizem ser Péssimo. $02 \%$ menciona ser excelente. Isso se relaciona que os atendentes são bons, mas ainda não conseguiu o grau de excelência de estar totalmente envolvido em atender as necessidades dos clientes, sendo assim a empresas deverão buscar a evolução que se almeja pelo consumidor através dos colaboradores, identificando as falhas e aplicando as mudanças. A empresa deverá buscar mudanças para diferenciar das concorrentes, onde a satisfação do cliente envolve todos os processos das organizações, unificada para a prestação de atendimento qualificado apresentado por Oliveira (2011).

Gráfico 06: O Atendimento do funcionário atende as suas expectativas.

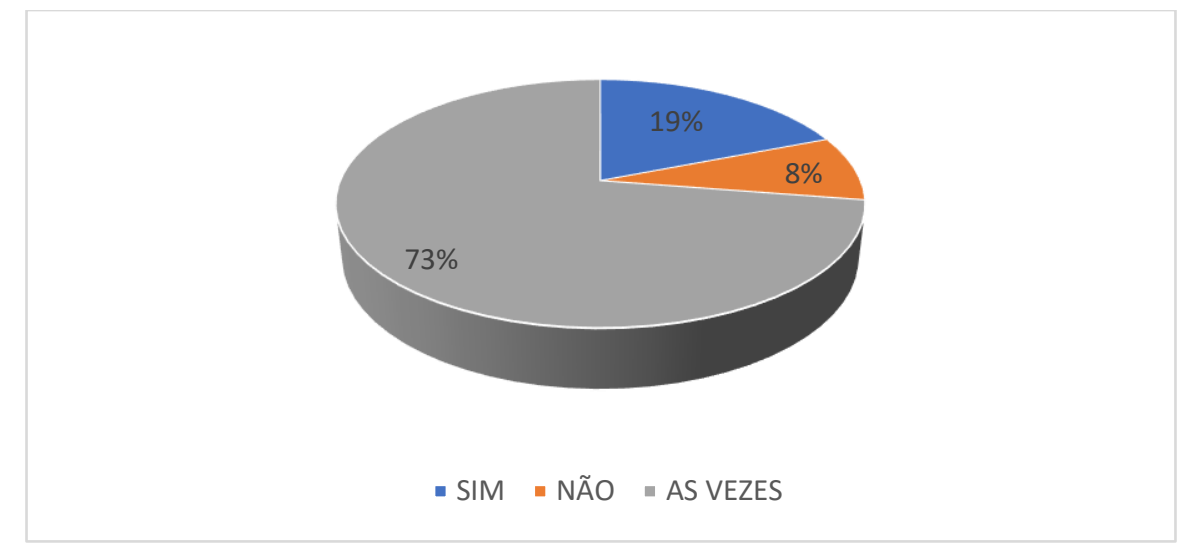

Fonte: Dados da pesquisa 2018.

O Gráfico 06 aponta que $73 \%$ dos entrevistados dizem que às vezes o atendimento atende as expectativas. $19 \%$ afirmam que sim atende e $8 \%$ falaram não atende. Tendo em vista que a grande 
maioria dos entrevistados relata que nem sempre os atendentes se coloca a disposição para analisar as necessidades e desejos do cliente, pode-se perceber que há falta de comunicação para esclarecimentos de dúvidas e acompanhamento das compra, averiguando que as empresas não estão atentas ao cliente.

O consumidor é responsável por toda alavancagem de crescimento organizacional, presumindo que as expectativas do consumidor incidem na satisfação, fazendo necessário atender estas expectativas do cliente de forma eficiente e com qualidade, confirmada por Gianesi e Corrêa (2012).

Gráfico 07: O que leva você comprar em uma empresa

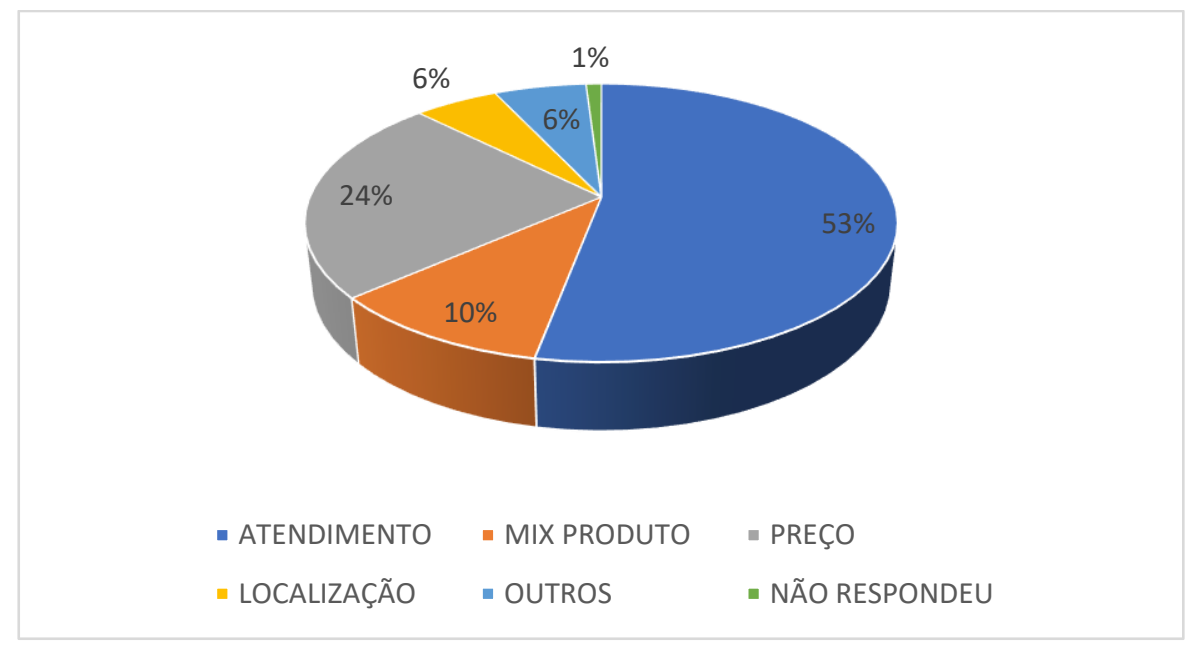

Fonte: Dados da pesquisa 2018.

O Gráfico 07 mostra que 53\% da maioria dos entrevistados, identificam o atendimento para realizar uma compra. Um percentual de $24 \%$ falaram preço e $10 \%$ disseram o mix de produto. É nítido que houve uma supremacia do atendimento, confirmando o que os autores falaram acerca de um atendimento com qualidade. O preço aparece na sequência como quesito relevante para comprar em uma empresa, porém os autores não aborda o preço como um fator importante. O mix de produto incidi também, levando a crer que o cliente busca diversidade de produtos para satisfazer as suas necessidades.

Quadro 02: O que precisa melhorar no atendimento ao cliente na cidade de Mauriti.

\begin{tabular}{|c|c|c|}
\hline $\begin{array}{c}160 \text { Pessoas } \\
\text { responderam }\end{array}$ & $\begin{array}{c}\text { Atendimento, gentileza, bom humor, Simpatia, } \\
\text { educação, dialogo, carisma, acolhimento, sorrir } \\
\text { mais. }\end{array}$ & \\
\hline $\begin{array}{c}40 \text { Pessoas } \\
\text { responderam }\end{array}$ & $\begin{array}{c}\text { Agilidade, qualidade do produto, conhecer mais } \\
\text { o produto e apenas uma pessoa respondeu o } \\
\text { preço. }\end{array}$ & \\
\hline
\end{tabular}

Fonte: Dados da pesquisa 2018. 
No quadro 02 foi elaborada uma pergunta sobre o que precisa ser melhorado no momento do atendimento ao cliente nos comércios da cidade citada. Dos 200 entrevistados 160 pessoas afirmou que para ocorrer um atendimento de qualidade as empresas precisam realizar procedimentos de satisfação através de qualidade fornecida pelos colaboradores, como realizar um bom atendimento, ter gentileza, bom humor, simpatia, educação, carisma, acolhimento e sorrir mais. Outras 40 pessoas identificaram a falta de agilidade, qualidade do produto e conhecer mais o produto, apenas uma pessoa respondeu o preço.

Analisa-se que para o crescimento das empresas os fatores essências estão na maneira de como os clientes estão sendo tratados pelos os colaboradores. É fundamental obter receptividade e acompanhamento no processo de compra, passando a ser prioridade, pois os clientes são pilares importantes para a existência de qualquer negócio. Esclarecido que não é preço dos produtos que tem a maior influência do resultado que se espera, mas os serviços prestados que fornecem maior controle para o retorno de investimentos. As empresas devem seguir princípios para garantir a satisfação do cliente através de comprometimento nas atividades e postura ética, gerando atendimento alinhado pela organização ao serviço que se deseja ao alcance dos consumidores mencionado por Carvalho e Morais (2010).

\section{Considerações Finais}

A qualidade no atendimento está ligada a valores que possibilitam a organização conhecer as necessidades e desejos dos clientes, buscando desta forma identificar como os serviços estão sendo desenvolvido. É fundamental que as empresas conheçam os hábitos de consumo e ofereça satisfação ao consumidor, adquirindo o alcance de bons resultados por meios de competências fornecidas pelo serviço e produto.

Perante o questionamento da pergunta de partida desse estudo se "a qualidade agregada ao atendimento impacta na satisfação ao consumidor? Foi respondida de maneira satisfatória ao identificar as influências do comportamento do consumidor, possibilidade da organização analisar as falhas e a priorizar o implante de sistemas técnicos que facilitem o cliente enxergarem a qualidade esperada através do atendimento, a exemplo disto à qualidade relacionada ao bom trato, simpatia, agilidade e confiança contribuída pelos os colaboradores. Agindo desta forma, a empresa ocasionará evolução de progredir no mercado competitivo. 
As hipóteses foram investigadas, confirmando que o atendimento é capaz de alterar todo o processo de uma empresa, proporcionando o aumento das vendas, quando possui qualidade agregada. Fornecer ao cliente bom atendimento é um método importante na gestão estratégica da empresa.

A pesquisa mostrou resultados de grande importância para as organizações, como conhecer as sugestões dos clientes para aplicação de investimentos sobre mudanças e inovações do atendimento que está sendo ofertado, entre outros processos que não estão alinhados, trazendo também resultado que possibilite as empresas fazerem tomadas de decisão perante os pontos fortes e fracos apresentados. Com está visão as empresas têm grandes chances de crescer no mercado, visto que a maior necessidade que os clientes identificam, que nem sempre recebem atendimento de qualidade, gerando insatisfação.

Ao fazer o estudo da pesquisa é notório que os objetivos foram realizados com total importância, deixando esclarecido através de análises e estudos teóricos que a qualidade no atendimento possui um grau de relevância ao proporcionar a satisfação ao cliente, entendendo que as empresas precisam estar atentas em satisfazer as necessidades do consumidor. $\mathrm{O}$ artigo mostrou a situação atual do comércio da cidade de Mauriti, porém fica a sugestão para futuros estudos, propostas de novas pesquisas e formas de implantação de sistemas de qualidade no atendimento ao cliente.

\section{Referências}

ALMEIDA, Maria Lucia Pacheco de. Tipos de pesquisa. In. Como elaborar monografia. 4. Ed. Ver. estual. Belém: Cejup, 1996. Cap. 4, p. 101-110.

ALVAREZ, Francisco. J. S. M. Gestão Estratégica de Clientes. 1 ed. São Paulo: Saraiva, 2015.

CARPINTTI, Ribeiro Cesar Luiz; GEROLAMO, Mateus Cecílio. Gestão da Qualidade. 1. ed. São Paulo: Altas 2015.

CARVAlHO, Marly Monteiro de; PALADINI, Edson Pacheco. Gestão da Qualidade: Teoria e Casos. 2. ed. Rio de Janeiro: Elsevier, 2012.

CARVAlHO, Pedro Carlos de; MORAIS, Wagner Froésde. Administração Mercadológica. 3. ed. Campinas: Alínea, 2010.

COBRA, Marcos Henrique Nogueira. Marketing Básico. 4. ed. São Paulo: 2015.

DANTAS, Edmundo Brandão. Gestão da Informação sobre a Satisfação de Consumidores e Clientes. 1 ed. São Paulo: Atlas, 2014.

DEFEO, Joseph A.; JURAN, Oseph, M. Fundamentos da Qualidade para Lideres. 1. ed. Porto Alegre: Bookman, 2015. 
GIANESI, Irineu. G. N.; CORRÊA, Henrique Luiz. Administração Estratégica de Serviços: Operações para a Satisfação do Cliente. 1 ed. São Paulo: Atlas, 2012.

KOTLER, Philip. Administração de Marketing. 14. ed. São Paulo: Saraiva, 2012.

LAS CASAS, Alexandre Luzzi. Marketing: Conceitos, Exercícios e Casos. 9. ed. São Paulo: Atlas, 2017.

LIMEIRA, Tania Maria Vidigal. Comportamento do Consumidor Brasileiro. 2. ed. São Paulo: Saraiva, 2017.

PALADINI, Pacheco Edson; BRIDI, Eduardo. Gestão e Avaliação da Qualidade em Serviços para Organizações Competitivas: Estratégias Básicas e o Cliente Misterioso. 1. ed. São Paulo: Atlas, 2013.

TERRA. Pesquisa Mostra que o Brasil é o Penúltimo Colocado em Simpatia no Atendimento a Clientes. São Paulo: Fev. ed. Online, 2018. Disponível em: <https://www.terra.com.br/noticias/dino/pesquisa-mostraque-o-brasil-e-o-penultimo-colocado-em-simpatia-no-atendimento-aclientes.html>. Acesso em: 08 set. 2018.

OLIVEIRA, Djalma de Pinho Rebouças de. Administração de Processos: Conceitos, Metodologias e Práticas. São Paulo: Atlas, 2011.

SAMARA, Beatriz Santos; MORSCH, Marco Aurélio. Comportamento do Consumidor: Conceitos e Casos. 1. ed. São Paulo: Pearson, 2012.

SERRA, Fernando Ribeiro; FERREIRA, Manuel Portugal; TORRES, Alexandre Pavan. Gestão Estratégica: Conceitos e Casos. 1 ed. São Paulo: Atlas, 2014.

SEVERINO, Antônio Joaquim. Metodologia do Trabalho Científico. 24. ed. São Paulo: Cortez, 2016.

SILVA, Fabio Gomes de; ZAMBON, Marcelo Socorro. Gestão de Relacionamento com o Cliente. 2. ed. São Paulo: Cengage Learning, 2012.

SOLOMON, Michael. O Comportamento do Consumidor: Comprando, Possuindo e Sendo. 11. ed. Porto Alegre: Bookman, 2016.

TAVARES, Mauro Calixta. Gestão Estratégica. 3. ed. São Paulo: Atlas, 2012.

WELLingTON, Pat. Atendimento Eficaz ao Cliente: Entenda as Necessidades, Aprimore o Atendimento, Fortaleça Relacionamento e Desenvolva a Lealdade de Seus Clientes. 1. ed. São Paulo: Clio Editora, 2011.

\section{Como citar este artigo (Formato ABNT):}

BENTO, Luciene de Lucena; LEITE, Márcia Maria Leite. Gestão da Qualidade com Foco no Atendimento ao Cliente: Estudo Realizado na Cidade de Mauriti-CE. Id on Line Rev.Mult. Psic., 2018, vol.12, n.42, p. 761-778. ISSN: 1981-1179.

Recebido: 19/10/2018;

Aceito: 22/10/2018 